\title{
REPORT OF THE RADIOCARBON IN SOILS WORKSHOP SATURDAY 13 AUGUST 1994
}

\section{PETER BECKER-HEIDMANN}

Institut für Bodenkunde, Universität Hamburg, Allende-Platz 2, D-20146 Hamburg, Germany

and

\section{DOUG HARKNESS}

\section{NERC Radiocarbon Laboratory, Scottish Enterprise Technology Park, East Kilbride G75 OQF, Scotland}

The Workshop was attended by 40 colleagues from different countries and disciplines, who populated the stalls and the dress circle of the main theater of the Royal Scottish Academy of Music and Drama. Because of the complexity of the agenda, various questions and topics were only touched upon; some others were discussed more deeply. Five oral presentations structured the field and animated the discussion. Some will be published either in the Conference Proceedings or in a special issue of RADIOCARBON.

Phil Ineson, Roland Bol and Doug Harkness, under the title "Great Dun Fell: A field experiment to evaluate the effects of climatic warming on the turnover of soil organic matter", presented results of their contribution to the British TIGER program on global change. The following discussion on "The art of soil sampling" included boundary effects of soil columns in DOC percolation studies, non-disturbing suction rates in soil gas analysis, accounting for biomass and the choice of horizon or 2-cm-layer soil sampling.

Steve Leavitt reported on his work with Eldor Paul and Ron Follett: "Estimation of slow and fastcycling soil organic pools from $6 \mathrm{~N} \mathrm{HCl}$ hydrolysis", followed by Roland Bol and Yongsong Huang on "Identification and preparation of soil carbon components for isotope analyses". Both presentations initiated an intense discussion on "sample preparation". Is there a standard method? How many times should one repeat $6 \mathrm{~N} \mathrm{HCl}$ treatment to receive the "real" recalcitrant fraction? What fractionation scheme is the best? Questions which could be answered only within the context of the aim of the specific study, i.e., whether it is archaeologically, pedogenetically or ecologically orientated. There is a strong need for methods to identify and isolate fractions which are relevant to carbon dynamics and which, up to now, have been only postulated, but frequently used by modelers. GC-IRMS and ${ }^{13} \mathrm{C}-\mathrm{NMR}$ are two of the possible candidates. For the "dating" of soils, pollen appears to be the most reliable fraction.

Luiz Pessenda continued with his presentation of "The use of carbon isotopes $\left({ }^{13} \mathrm{C},{ }^{14} \mathrm{C}\right)$ in soil to evaluate vegetation changes during the Holocene in Central Brazil", co-authored by R. Aravena, A.J. Melfi, E. C.C. Telles, R. Boullet, E. P. E. Valencia and M. Tomazello. This opened a discussion on the "interpretation of data and modeling soil/plant systems". How can we distinguish among the shift of $\delta^{13} \mathrm{C}$ of soil organic matter from the top to deeper layers caused by decomposition, by a change of $\mathrm{C}_{3}$ to $\mathrm{C}_{4}$ vegetation, and by methane production? How do we interpret ${ }^{14} \mathrm{C}$ dates of carbonate?

Interpretation of ${ }^{14} \mathrm{C}$ dates of soil carbon in most cases requires some kind of modeling. On the other hand, for models to produce consistent and plausible results, a more expanded data base is needed. As recent global carbon budget calculations have pointed to the biosphere and pedosphere as the most probable candidates for the "missing sink", soil carbon has become a key research target. Aus- 
tin Long talked about the efforts made to establish an International Radiocarbon Soils Data Base (IRSDB), which started in Tucson in 1992 with a workshop where its structure was set up. It is planned to be made accessible via the Internet, and every laboratory that has dated soils is encouraged to contribute. Also, the actually available dates will be put together either as original figures or, if already published, as annotated references and published in a special issue of RADIOCARBON.

The workshop brought together ${ }^{14} \mathrm{C}$ daters as well as consumers and soil scientists. As one participant said, "we already had all the questions discussed here, 30 years ago", but meanwhile, as we could learn, the sampling technique has improved, new, promising methods of analysis and fractionating of the soil have appeared, and the modelers have begun to take more care of the soil carbon. 